\title{
A 64-year-old woman with raccoon eyes following kidney biopsy: a case report
}

\author{
Shuqin Mei ${ }^{1}$, Yunyang Zhao ${ }^{2}$, Lin $\mathrm{Li}^{1}$, Changlin Mei ${ }^{1}$ and Bing Dai ${ }^{*}$
}

\begin{abstract}
Background: Raccoon eyes or periorbital ecchymosis is caused by blood tracking into periorbital tissues, which is mostly recognized in injuries of head and neck, basal skull fractures, convexity fractures and facial fractures. It was also reported in systematic disorders, such as multiple myeloma, amyloidosis, Kaposi's sarcoma, migraine and neuroblastoma. However, it is unusual to see a patient showing periorbital purpura after kidney biopsy with no other ecchymosis. Here, we firstly reported this rare symptom after kidney biopsy in a patient who was finally diagnosed as immunoglobulin light chain (AL) amyloidosis.

Case presentation: A 64-year old woman was admitted to our clinic with 1.5 years history of sub-nephrotic proteinuria and slowly progressive deterioration of renal function. Laboratory -investigations revealed an M-peak in the $\lambda$ fraction of IgA and concentrations of serum free-light-chain (FLC) were $44.95 \mathrm{mg} / \mathrm{L}$ for $\mathrm{K}$ isotype and $173 \mathrm{mg} / \mathrm{L}$ for $\lambda$ isotype. Unexpectedly the patient showed periorbital purpura $24 \mathrm{~h}$ later after kidney biopsy with no more other ecchymosis. Renal biopsy showed massively glomerulosclerosis, interstitial fibrosis with positively Congo red staining in mesangial areas. For fluorescent staining, the kidney tissue showed strongly $\lambda$ light-chain deposition. The fibrils (8-12 nm in diameter) were confirmed by electron micrograph.

Conclusions: This case firstly reported this rare symptom after the kidney biopsy in a patient who was finally diagnosed as AL amyloidosis. And this unique sign of periorbital ecchymosis warrants more attention as an early cue of amyloidosis.
\end{abstract}

Keywords: Raccoon eyes, Periorbital purpura, Kidney biopsy, Immunoglobulin light chain amyloidosis

\section{Background}

Raccoon eyes or periorbital ecchymosis is caused by blood tracking into periorbital tissues, which is easily recognized as a common symptom of injuries of head and neck, basal skull fractures, convexity fractures and facial fractures. Also, some studies showed periorbital ecchymosis as a symptom of systematic disorders, such as multiple myeloma, amyloidosis, Kaposi's sarcoma, migraine and neuroblastoma. The coagulopathy and vascular infiltration of amyloid fibrils in peri-orbital blood vessels in patients with amyloidosis can cause bilateral

\footnotetext{
* Correspondence: czdaibing@smmu.edu.cn

${ }^{1}$ Kidney Institute of PLA, Department of Nephrology, Shanghai Changzheng Hospital, Naval Medical University, Shanghai, China

Full list of author information is available at the end of the article
}

periorbital ecchymosis by minimal trauma, such as coughing, sneezing, rubbing or Valsalva maneuver. In 2017, Nasiri reported a case of bilateral periorbital ecchymosis following Endoscopic retrograde cholangiopancreatography (ERCP) and sphincterotomy [1].

Yet, periorbital ecchymosis was rare to see following kidney biopsy. Here we firstly reported a case of bilateral periorbital ecchymosis (raccoon eyes) in a 64-year old woman $24 \mathrm{~h}$ later after the kidney biopsy who was finally diagnosed as AL amyloidosis.

\section{Case presentations}

A 64-year old woman presented to our clinic with 1.5 years history of proteinuria (the 24-h urine protein quantification was between $0.9-1.5 \mathrm{~g}$ ). Renal function

\section{$\triangle B M C$}

(c) The Author(s). 2020 Open Access This article is licensed under a Creative Commons Attribution 4.0 International License, which permits use, sharing, adaptation, distribution and reproduction in any medium or format, as long as you give appropriate credit to the original author(s) and the source, provide a link to the Creative Commons licence, and indicate if changes were made. The images or other third party material in this article are included in the article's Creative Commons licence, unless indicated otherwise in a credit line to the material. If material is not included in the article's Creative Commons licence and your intended use is not permitted by statutory regulation or exceeds the permitted use, you will need to obtain permission directly from the copyright holder. To view a copy of this licence, visit http://creativecommons.org/licenses/by/4.0/ The Creative Commons Public Domain Dedication waiver (http://creativecommons.org/publicdomain/zero/1.0/) applies to the data made available in this article, unless otherwise stated in a credit line to the data. 
deteriorated gradually (the serum creatinine increased from $130 \mathrm{umol} / \mathrm{L}$ to $382 \mathrm{umol} / \mathrm{L}$ ) with no history of hypertension (usually $95 / 60 \mathrm{mmHg}$ ), diabetes and other significant medical history.

Physical examination was unremarkable. Laboratory study showed mild anemia of $\mathrm{Hb}$ was $97 \mathrm{~g} / \mathrm{L}$ and normal coagulation test. Serum creatinine was increased at 382 umol/L and the 24-h urine protein quantification was $2.4 \mathrm{~g}$. The ratio of $\mathrm{k} / \lambda$ in the serum and urine proteins were normal. While, the testing for monoclonal protein by serum revealed an M-peak in the $\lambda$ fraction of IgA (Fig. 1a). With the help of the serum free-light-chain (sFLC) assay, we got the concentrations of sFLC were $44.95 \mathrm{mg} / \mathrm{L}$ for $\mathrm{\kappa}$ isotype and $173 \mathrm{mg} / \mathrm{L}$ for $\lambda$ isotype. The ratio of $\kappa$ to $\lambda$ was $0.26(1.26-1.65)$. The bone marrow cytology test was negative. Echocardiographic findings showed the normal interventricular septum thickness which was $9 \mathrm{~mm}$ and $\mathrm{EF}$ was about $63 \%$. Abdominal ultrasound report indicated enhanced echo of liver parenchyma and normal spleen appearance. The size of right kidney was $9.1 \times 4.4 \mathrm{~cm}$ and the left kidney was $10 \times 4.1 \mathrm{~cm}$. Enhanced cortical echo, clear demarcation between cortex and medulla, normal collecting system with no pyelic separation was recorded by ultrasound. Also, electromyography and nerve conduction velocity studies showed negative results.

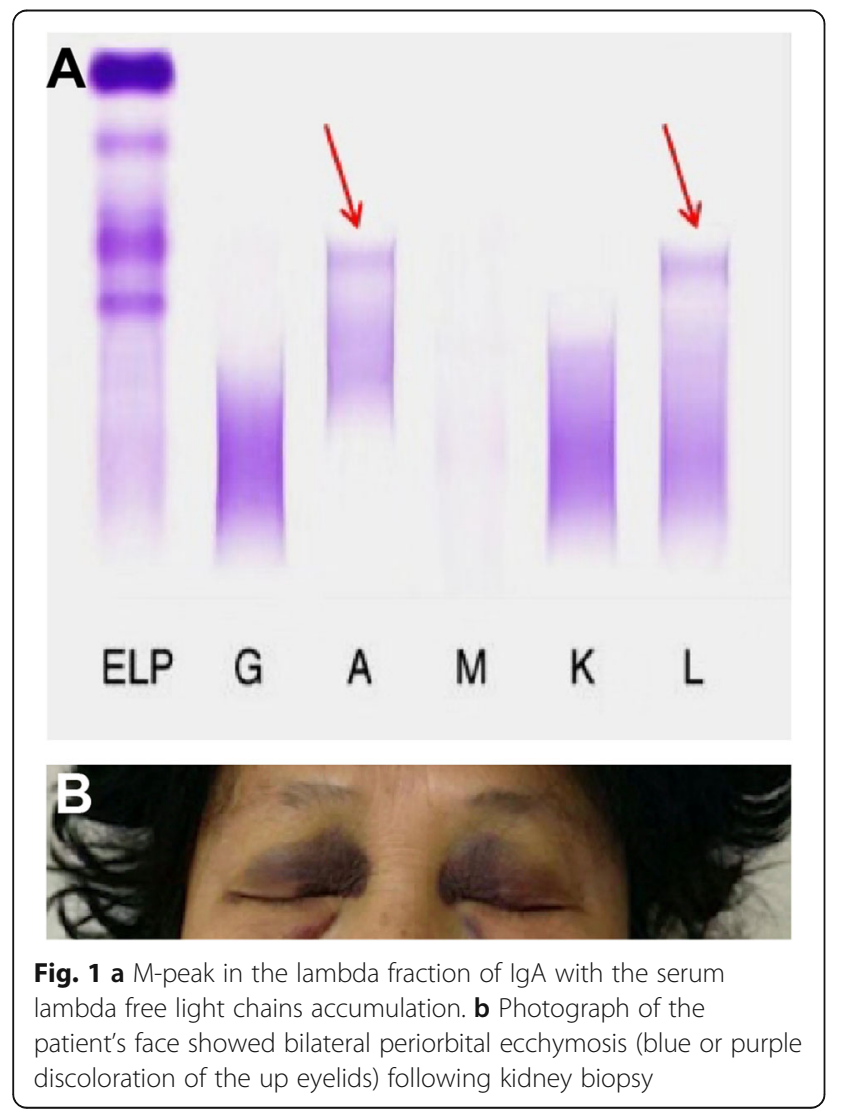

In order to figure out whether the kidney lesions belong monoclonal gammopathy of renal significance (MGRS), we performed kidney biopsy, and the patient showed periorbital purpura $24 \mathrm{~h}$ later after kidney biopsy with no more other ecchymosis (Fig. 1b).

Eighteen glomeruli were sampled, all of which were glomerulosclerosis. The volume of the glomeruli was increased, accompanying with the mild to severe enlargement of mesangial areas. Renal tubular epithelial cells were swollen, degenerated and necrosis. $70-80 \%$ interstitial were fibrotic with a small number of inflammatory cells infiltration. Congo red staining was positive and typical apple-green birefringence was showed under polarized microscopy (Fig. 2a). For fluorescent staining, the kidney tissue showed strongly $\lambda$ light-chain deposition (Fig. 2b). Electron micrograph showing expansion of the mesangium by amyloid fibrils, and the fibrillar appearance was best appreciated by the arrow (Fig. 2d). These fibrils $(8-12 \mathrm{~nm}$ in diameter) are smaller than those seen in fibrillary and immunotactoid glomerulonephritis. A diagnosis of immunoglobulin light chain (AL) amyloidosis nephropathy was established. Then the patient received 2 cycles of cyclophosphamide, bortezomib, and dexamethasone. The 24-h urine protein quantification was around $0.6 \mathrm{~g}$ and the serum creatinine decreased to $306 \mathrm{umol} / \mathrm{L}$.

\section{Discussion and conclusion}

$\mathrm{AL}$ amyloidosis is the most common type of systemic amyloidosis, which is difficult to recognize because of the vague symptoms and range of manifestations. While, the key features of all kinds of amyloidosis is abnormal folding of a protein that is normally soluble and can be typical apple-green birefringence with polarized microscopy after Congo red dye [2, 3]. As is known to all, there are several major forms of amyloidosis, including immunoglobulin light chain (AL) amyloidosis, amyloid A (AA) amyloidosis, dialysis-related amyloidosis, heritable amyloidosis. And AL amyloidosis is the most common type of systemic amyloidosis. The pathogenesis of $\mathrm{AL}$ amyloidosis is an Ig light chain or the fragment of a light chain which is produced by a population of abnormal plasma cells in the bone marrow. Comparing to multiple myeloma, the cell burden in AL amyloidosis is lower, usually less than $10 \%$. The accumulated fibrils in AL amyloidosis derive from the variable region of $\lambda$ light chains in approximately $75 \%$ of cases, and $\kappa$ light chains are responsible for the remainder.

Renal involvement accounts for almost $70 \%$ of patients with AL amyloidosis and most often presents as clinically apparent nephrotic syndrome and enlarged kidney size [4]. Sometimes it is insidious, only presented with proteinuria and slowly progressive deterioration of renal function with unknown etiology. So it is necessary to 

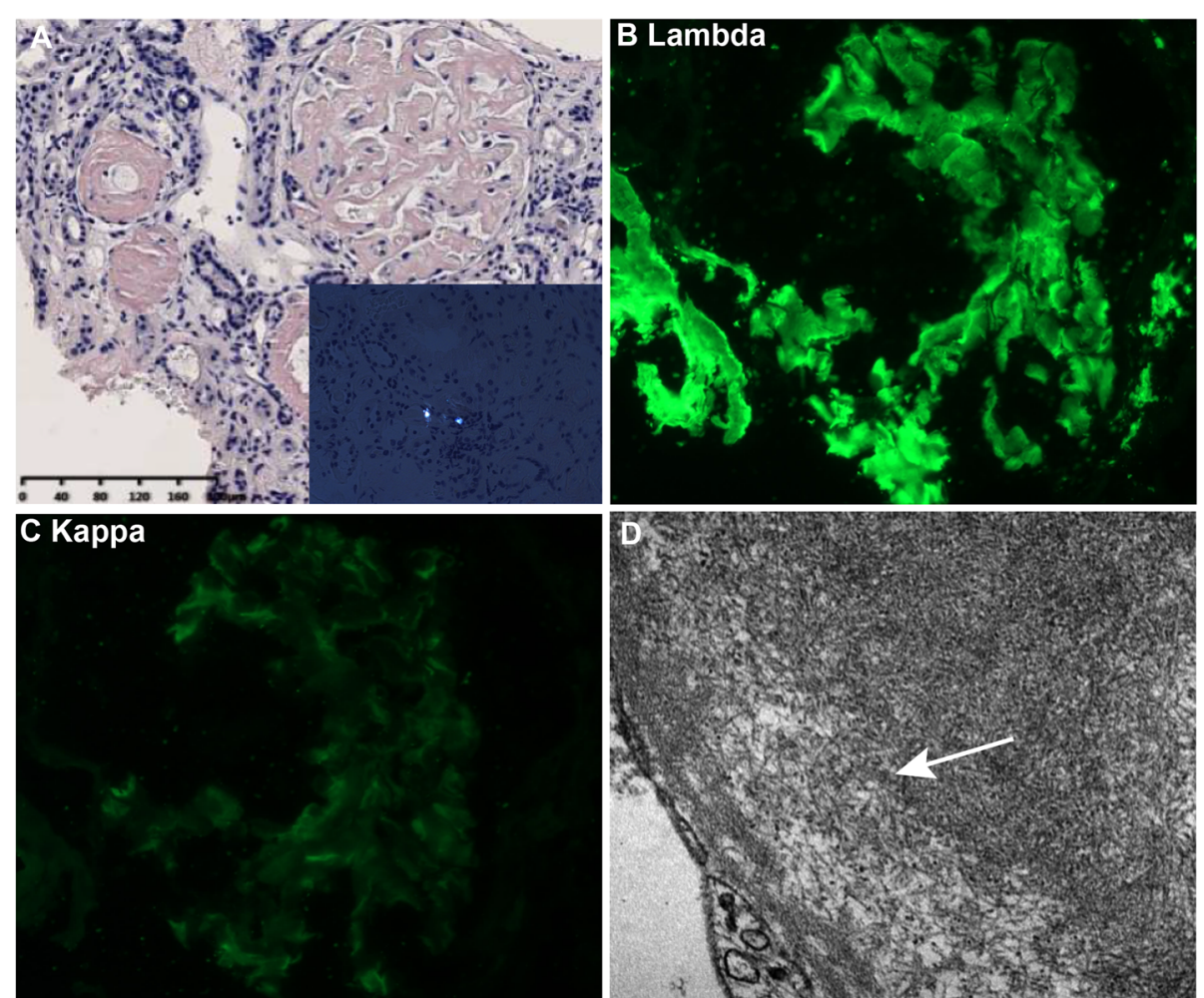

Fig. 2 a Congo red staining of kidney biopsy specimen and the picture of typical apple-green birefringence under polarized microscopy ( $\times 200)$. b and $\mathbf{c}$ Immunofluorescence microscopy showed prominent staining for lambda light chain and much weaker kappa light chain $(\times 400)$. d Electron micrograph showing expansion of the mesagium by amyloid fibrils, which can measure $8-12 \mathrm{~nm}$ in diameter. The fibrillar appearance is best appreciated at the arrow $(\times 10,000)$

perform tissue biopsy (kidney, abdominal fat pad and other affected sites), once the patients with unknown renal failure accompany with monoclonal $\mathrm{M}$ protein or suspicious tissue infiltration.

Periorbital ecchymosis is caused by blood tracking into periorbital tissues, which are easily recognized and generally thought as a common symptom of basal skull fractures. However, it may be a sign of health threatening situations such as multiple myeloma, amyloidosis, Kaposi's sarcoma and neuroblastoma. Usually, periorbital ecchymosis in AL amyloidosis is called "raccoon eyes" and is caused by vascular infiltration of amyloid fibrils in peri-orbital blood vessels. Other causes of peri-orbital bleeding including clotting disorders, trauma, essential thrombocytaemia [5]. Here we firstly reported this rare symptom after the kidney biopsy in a patient who was finally diagnosed as AL amyloidosis. During the kidney biopsy, the patient was asked to hold breath after inhalation, which mimicked Valsalva maneuver, and thus contribute to the periorbital purpura. Therefore, periorbital ecchymosis warrants more attention as an early cue of amyloidosis and it also can occur after an invasive diagnostic procedure such as renal biopsy.

\section{Abbreviations}

AL amyloidosis: Immunoglobulin light chain amyloidosis; AA amyloidosis: Amyloid A amyloidosis; sFLC: Serum free-light-chain; ERCP: Endoscopic retrograde cholangiopancreatography; MGRS: Monoclonal gammopathy of renal significance

\section{Acknowledgements}

All authors thank the patient and her family for their support.

\section{Authors' contributions}

SQM, YYZ, LL, CLM and BD were all directly involved in the care of this patient. SQM and YYZ collected the data necessary for analysis and wrote the initial draft of the paper. LL and CLM contributed to the data analysis and interpretation. BD was responsible for revising the manuscript. All authors read and approved the final manuscript.

\section{Funding}

This paper was supported by The National Natural Science Foundation of China (grant No. 81800681). The finding sources had no role in the design of the study; collection; analysis and the interpretation of the data; or writing of the manuscript.

Availability of data and materials

All data collected from this patient were obtained from Changzheng Hospital and are available in this paper.

Ethics approval and consent to participate Not Applicable. 


\section{Consent for publication}

The patient received all information regarding this case report. Written informed consent for publication in BMC Nephrology was obtained from the patient. A copy of the consent form is available for review by the Editor of this journal.

\section{Competing interests}

The authors declare that they have no competing interests.

\section{Author details}

"Kidney Institute of PLA, Department of Nephrology, Shanghai Changzheng Hospital, Naval Medical University, Shanghai, China. ${ }^{2}$ Department of Hematology, Shanghai Changzheng Hospital, Naval Medical University,

Shanghai, China.

Received: 7 October 2019 Accepted: 19 March 2020

Published online: 17 April 2020

\section{References}

1. Heegaard NH. Beta(2)-microglobulin: from physiology to amyloidosis. Amyloid. 2009;16:151-73.

2. Nasiri J, Zamani F. Periorbital ecchymosis (raccoon eye) and orbital hematoma following endoscopic retrograde Cholangiopancreatography. Case Rep Gastroenterol. 2017;11:134-41.

3. Eisenberg $D$, Jucker $M$. The amyloid state of proteins in human diseases. Cell. 2012;148:1188-203.

4. Said SM, Sethi S, Valeri AM, et al. Renal amyloidosis: origin and clinicopathologic correlations of 474 recent cases. Clin J Am Soc Nephrol. 2013;8:1515-23.

5. Eder $\mathrm{L}$, Bitterman $\mathrm{H}$. Image in clinical medicine. Amyloid purpura. The New England J Med. 2007;356:2406.

\section{Publisher's Note}

Springer Nature remains neutral with regard to jurisdictional claims in published maps and institutional affiliations.

- fast, convenient online submission

- thorough peer review by experienced researchers in your field

- rapid publication on acceptance

- support for research data, including large and complex data types

- gold Open Access which fosters wider collaboration and increased citations

- maximum visibility for your research: over $100 \mathrm{M}$ website views per year

At $\mathrm{BMC}$, research is always in progress. 